\title{
DELIMITAÇÃO ESPACIAL DE UMA UNIDADE DE CONSERVAÇÃO: O CASO dA ÁREA DE PROTEÇÃo AMBIENTAL DO VACACAÍ-MIRIM/RS
}

\section{DELIMITATION OF SPACE OF A CONSERVATION UNIT: THE CASE OF AREA OF ENVIRONMENTAL PROTECTION VACACAÍ-MIRIM/RS}

\author{
Dalvana Brasil do Nascimento \\ Mestre em Geografia \\ Universidade Federal de Santa Maria \\ dbngeo@hotmail.com \\ Eliane Maria Foleto \\ Professora Doutora do Departamento de Geociências \\ Universidade Federal de Santa Maria \\ efoleto@gmail.com
}

\begin{abstract}
RESUMO
A Área de Proteção Ambiental(APA)do Vacacaí-Mirimainda não foi instituída e está em processo de discussão. O objetivo geral deste trabalho é apresentar uma proposta de delimitação para a mesma, comparando à proposta de NASCIMENTO (2010). A partir do método dedutivo de pesquisa científica e da abordagem sistêmica buscou-se atingir tal objetivo por meio do conceito de paisagem, configurando-se como uma contribuição geográfica aos estudos ambientais. Os resultados demonstraram que os remanescentes de Mata Atlântica mais conservados na área de estudo encontram-se na unidade da paisagem Rebordo do Planalto. A delimitação propostaapresenta um formato mais adequado à conservação, diminuindo o efeito de borda sobre a vegetação e aumentando a abrangência da mesma, somando aproximadamente $88 \mathrm{~km}^{2}$.
\end{abstract}

Palavras-chave: Unidades de Conservação. Área de Proteção Ambiental. Paisagem. Santa Maria. Itaara. 


\begin{abstract}
The Area of Environmental Protection of Vacacaí-Mirim has not yet been established and is in the process of discussion. The general objective this paper consists on presenting a proposal to delimitate the area, comparing the proposed by NASCIMENTO (2010). Through a deductive method of research and a systemic approach, tried to achieve the objective through the concept of landscape, making it a geographic contribution to environmental studies. The results showed that the more conserved Mata Atlântica remaining can be found in the Rebordo do Planalto landscape unit.The delimitation proposal presents a format more suitable for conservation, reducing the edge effect on vegetation and increasing the breadth of it, adding approximately $88 \mathrm{~km}^{2}$.
\end{abstract}

Keywords: Conservation Units. Area of Enviromental Protection.Landscape. Santa Maria. Itaara.

\title{
INTRODUÇÃO
}

A Área de Proteção Ambiental (APA) foi integrada ao Sistema Nacional de Unidades de Conservação da Natureza/SNUC (Lei $n^{\circ}$ 9.985) em 2000, fazendo parte do grupo de uso sustentável e tendo por objetivo proteger a diversidade biológica, disciplinar o processo de ocupação e assegurar a sustentabilidade do uso dos recursos naturais (BRASIL, 2000).

Em meados do ano de 2005, representantes do Escritório Regional de Santa Maria do Instituto Brasileiro do Meio Ambiente e dos Recursos Naturais Renováveis (Ibama) apresentaram uma proposta visando à criação da APA do Vacacaí-Mirim, na bacia hidrográfica do Rio Vacacaí-Mirim à montante de seu barramento, nos municípios de Santa Maria e Itaara, no Rio Grande do Sul.

Esta APA tinha como principal finalidade a proteção dos recursos hídricos, porém, a Unidade de Conservação (UC) não fora instituída, mas a proposição foi retomada em 2009 e discussões tem ocorrido no meio político, social e acadêmico de tais municípios.

A área na qual se pretende criar a UC possui atributos importantes, destacandose por fazer parte do tombamento da Reserva da Biosfera da Mata Atlântica no estado 
do Rio Grande do Sul pela Organização das Nações Unidas para a Educação a Ciência e a Cultura-UNESCO, desde 1993 (CONSELHO NACIONAL DA RESERVA DA BIOSFERA DA MATA ATLÂNTICA, 2008). Também, existem legislações municipais referentes a esta reserva, assim como a outras denominações de áreas protegidas projetadas para este espaço.

Diante do exposto, a problemática deste trabalho é a seguinte: qual delimitação espacial seria adequada ao estabelecimento da APA do Vacacaí-Mirim? Busca-se responder a esta questão a partir do conceito de paisagem, objetivando-se distinguir unidades de paisagem na ampla área de estudo para após delimitá-la e compará-la à proposta de NASCIMENTO (2010). Ainda, espera-se que os apontamentos apresentados sejam pertinentespara a instituição e para um posterior planejamento ambiental desta UC.

\section{APA: A bUSCA PELA PROTEÇÃo CONCOMITANTE À UTILIZAÇÃo DIRETA DOS RECURSOS AMBIENTAIS}

Conforme Viana e Ganem (2005) a introdução da APA no Brasil no início da década de 1980 representou importante inovação, pois propunha compatibilizar a conservação ambiental ao uso sustentável dos recursos, ainda, mediante a permanência das ocupações humanas dentro de seus limites. Em 2000, com o advento do SNUC, a APA foi incorporada ao sistema.

Esta UC é em geral uma área extensa, com um certo grau de ocupação humana, dotada de atributos abióticos, bióticos, estéticos ou culturais especialmente importantes para a qualidade de vida e o bem-estar das populações humanas, e tem como objetivos básicos proteger a diversidade biológica, disciplinar o processo de ocupação e assegurar a sustentabilidade do uso dos recursos naturais (BRASIL, 2000).

O grande valor de uma APA está na possibilidade de convivência do ser humano com o meio natural e demais formas de vida, inclusive, podendo existir em parcela de seu território ocupação antrópica como áreas urbanas e cultivos agrícolas.

Ao ser instituídaa APA deverá possuir um Conselho Gestor consultivo ou deliberativo composto por órgãos ambientais públicos dos três níveis da Federação, quando possível, como órgãos de áreas afins: pesquisa científica, educação, defesa 
nacional, cultura, turismo, paisagem, arquitetura, arqueologia, povos indígenas e assentamentos agrícolas (BRASIL, 2002 a).

A sociedade civil também deve estar representada neste conselho, contemplando quando couber, a comunidade científica e organizações ambientalistas com atuação comprovada na região de abrangência da unidade, a população residente em seu interior e entorno, os proprietários de imóveis no interior da APA, representantes do comitê de bacia hidrográfica, como trabalhadores e setor privado atuantes na região. Em casos de UCs públicas municipais o Conselho Municipal de Defesa do Meio Ambiente poderá ser designado como o Conselho Gestor da unidade, já que seus membros representam órgãos públicos e sociedade civil (BRASIL, 2002 b).

O conselho que irá gerir a APA deverá elaborar e aprovar um Plano de Manejo para a mesma, em um prazo de 5 anos a partir da data de sua criação (BRASIL, 2000). Cabral e Souza (2005) afirmam que o grande desafio na gestão de tal UC é balancear os interesses individuais, possibilitando assim a proteção dos ecossistemas. Este plano disporá sobre as normas de gestão ambiental da APA, estabelecendo os tipos de usos e ocupações humanas que poderão ser realizados, portanto se faz imprescindível a participação de todos os entes já citados nas discussões sobre o mesmo.

Para que ocorra esta discussão e sejam estabelecidas as diretrizes para a gestão da unidade o plano também deve conter o levantamento socioambiental da área e um conjunto de materiais cartográficos da mesma, auxiliando na elaboração do zoneamento da UC, onde, para cada zona estipulada será designado determinado tipo de uso e ocupação.

Administrar uma APA implica na necessidade de dispor de recursos financeiros. Bensusan (2006) trata sobre esta questão, já que o contexto brasileiro em relação às UCs é de carência financeira, mesmo existindo alguns mecanismos de captação de recursos para estas. O ICMS (Imposto sobre a Circulação de Mercadorias e Serviços) Ecológico é um deles e estimula o uso dos recursos na criação e manutenção de UCs. A Constituição Federal do Brasil (1988) prevê que cada estado deve efetuar a distribuição dos recursos obtidos com este imposto, sendo $25 \%$ do total destinados aos municípios. Os estados têm a autoridade de determinar os critérios de distribuição de $25 \%$ deste montante pelos municípios, influenciando assim nas prioridades dos municípios e estimulando certas atividades, como a proteção ambiental. 
Reforça-se então que, não se trata somente de benefícios ambientais que favorecem ecossistemas e proporcionam uma melhor qualidade de vida à população, mas também de melhoramentos de cunho socioeconômico.

Pensemos no setor de ensino, a UC seria um polo de disseminação da educação ambiental, mas também no setor produtivo, para exemplificar, produtores de alimentos do interior da UC podem ter seus produtos vinculados ao nome da APA, promovendoos no mercado; empresários poderão atrelar seus empreendimentos à proteção ambiental; a UC poderá ser um atrativo ecoturístico, estimulando a visitação, que movimenta o setor de serviços da região como demanda de guias ecoturísticos para realizar trilhas interpretativas, podendo estes ser provenientes dos próprios moradores do interior da APA.

Apesar de todos os benefícios já elencados é pertinente abordar também alguns aspectos negativos relacionados às APAs. Pádua (2011) afirma que tal categoria de UC prolifera, ao ponto de existir APA no nível estadual com 6 milhões de hectares. Ainda, que este tipo de unidade serviria mais como zona tampão para outras UCs, ou, para formar corredores ecológicos. A autora continua:

(...) É só se visitar a maioria das APAs que o país possui, onde prevalece a devastação. No passado, até um bairro na cidade do Rio de Janeiro foi considerado APA. Na Constituição do Estado do Pará, toda a ilha do Marajó é considerada APA, com 6 milhões de hectares. Também é verdade que algumas APAs vêm sendo bem manejadas, como as do sul da Bahia, ou algumas de Minas Gerais, ou a de Guaraqueçaba, no Paraná e a da Baleia Franca, em Santa Catarina, dentre outras. O fato de a terra continuar em mãos de particulares restringe de muito a possibilidade de real proteção (PÁDUA, 2011, p. 26-7).

Firkowski (2007) também faz severas críticas às APAs, afirmando que a função desta categoria estaria plenamente atendida se fossem cumpridos o Código Florestal (1965) e legislações complementares.

Esforcei-me, mas minha conclusão é que essa tal de APA nada mais é do que o mínimo desejável em termos de uso e ocupação do espaço: inteligente, técnico, viável e obedecendo à lei, com o suporte necessário e indispensável do Estado por intermédio de um serviço de extensão que qualquer cidadão, que paga uma fortuna de impostos, merece (Firkowski, 2007, p. 9-10). 
Frente a esta problematização e a pertinência da mesma, ainda crê-se que a instituição de UCs de uso sustentável, como a APA, pode ser um instrumento eficaz à conservação.

A eficácia desta categoria de UC na promoção da proteção ambiental e do bemestar das populações deve atender à sustentabilidade, considerando tanto as rígidas restrições de uso e ocupação em áreas onde o zoneamento determinar a preservação (CABRAL; SOUZA, 2005), quanto à utilização de seus recursos de modo adequado pelos seus residentes, ocupantes e visitantes da mesma.

\section{APRESENTAÇÃO DO OBJETO DE ESTUDO}

A ampla área de estudo desse trabalho situa-se na porção central do Rio Grande do Sul, nos territórios municipais de Santa Maria e Itaara, conforme a visualiza-se na figura 1.

Salienta-se que a APA do Vacacaí-Mirim não é uma UC instituída, o que existe até o momento são projetos, propostas e discussões a respeito da mesma. A categorização como APA dá-se devido às características do espaço geográfico estudado, que apresenta interferências antrópicas rural e urbana, como posse e domínio público e privado das terras. Portanto, esta é a categoria mais coerente frente às tipologias de UCs existentes.

Na figura 1 há destaque para as Reservas Particulares do Patrimônio Natural (RPPNs) outra categoria presente no Sistema Nacional de Unidades de Conservação da Natureza. A primeira RPPN a ser instituída no município de Itaara poderá ser a da organização ambientalista Fundação MO’Ã, onde esta vontade já culminou na elaboração de um projeto de lei, visando à instituição RPPNs Municipais.

Já em Santa Maria foi aprovada no primeiro semestre de 2010 a Lei n ${ }^{\circ} 5.285$ de 15/01/2010, que dispõe sobre a criação de RPPNs, gerada a partir da iniciativa da Igreja Episcopal Anglicana do Brasil ao solicitar o auxílio da Fundação MO’Ã para criar uma UC desta categoria. A área destinada a esta reserva encontra-se à jusante da Barragem do DNOS.

Ainda existe o projeto "Bosques Nativos", do Clube do Professor Gaúcho, que tem sua sede a nordeste da barragem, muito próxima a esta. Este busca transformar tal espaço em uma referência em educação ambiental, inclusive com a visitação de 
escolares e da comunidade em geral. Há vontade deste clube em, também, instituir uma RPPN.

Como exposto há um contexto de instituição de UCs nestas municipalidades, motivando tal trabalho e o debate sobre a conservação ambiental na região. Coincidindo a este contexto, no ano de 2010 o Ministério do Meio Ambiente publica um roteiro que trata exclusivamente sobre o incentivo à criação de UCs na esfera municipal, fortalecendo o que já tem sido realizado nos citados municípios. 

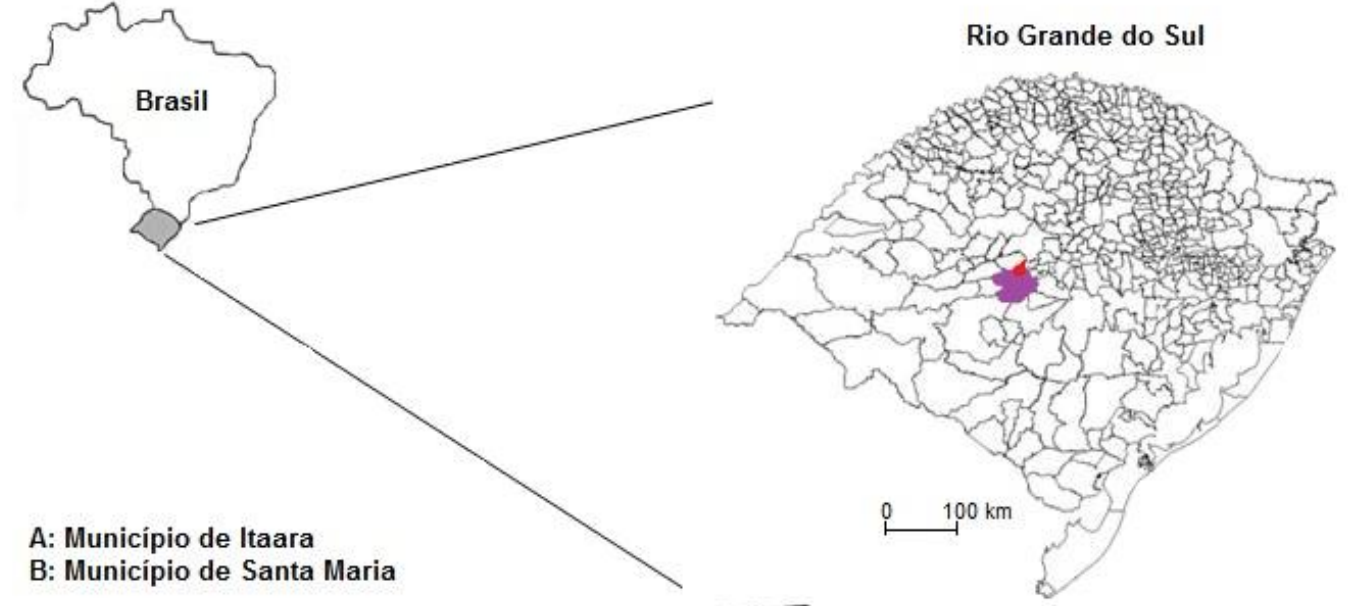

B: Município de Santa Maria

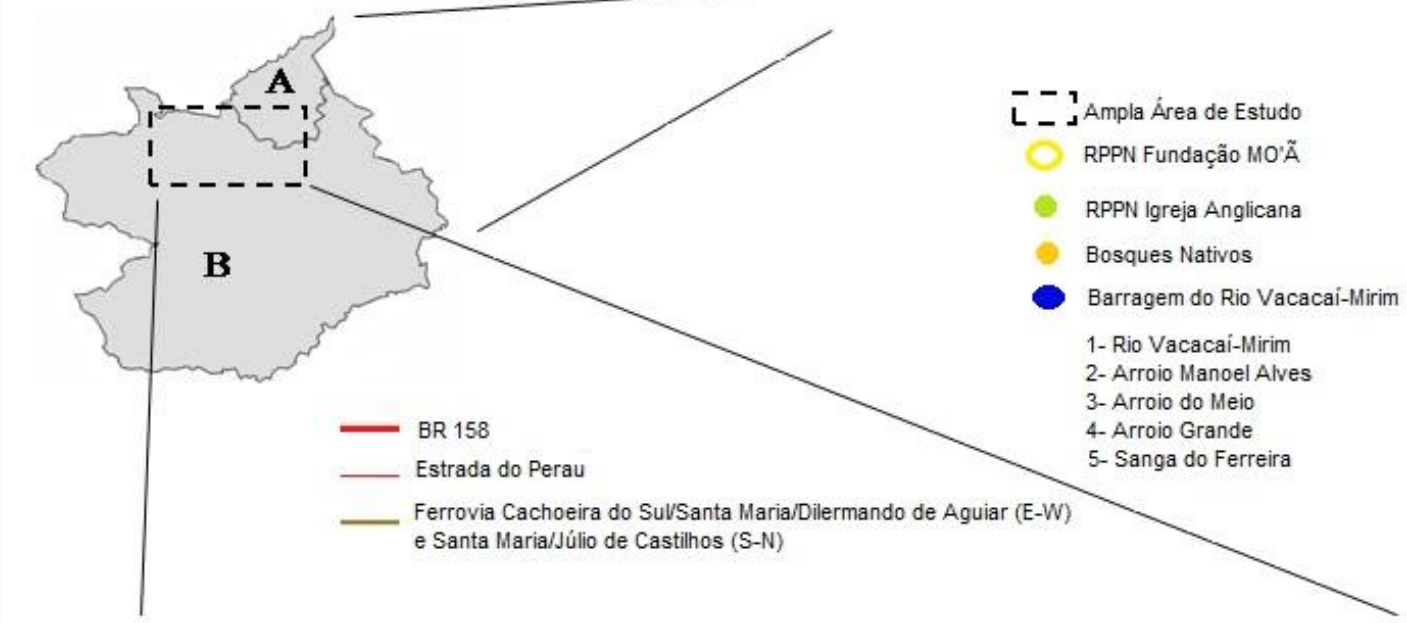

S $29^{\circ} 36^{\prime \prime} 29^{\prime \prime}$

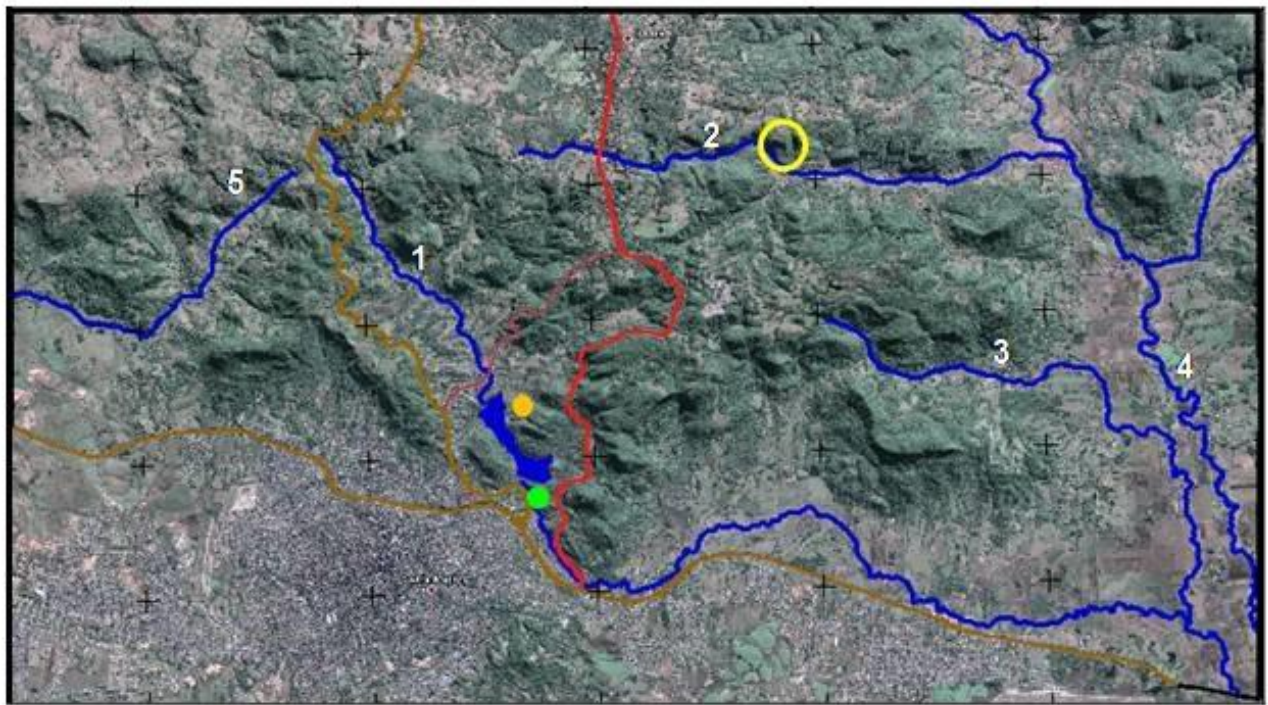

W $53^{\circ} 50^{\prime} 53^{\prime \prime}$

W $53^{\circ} 48^{\prime \prime} 32^{\prime \prime}$

W $53^{\circ} 46^{\prime} 11^{\prime \prime}$

W $53^{\circ} 43^{\prime} 50^{\prime \prime}$

W $53^{\circ} 41^{\prime 2} 29^{\prime \prime}$

Figura 1: Localização da ampla área de estudo. Destaque para os principais rios, estradas, ferrovias e projetos deRPPNs.

Fonte: NASCIMENTO, 2012 (modificado). 
Em novembro de 2010 ocorreu a oficialização e nomeação do Grupo de Trabalho para a Discussão de Parques Municipais e Unidades de Conservação, pelo Prefeito Municipal de Santa Maria. Com este advento crê-se que poderão ocorrer avanços quanto à criação de UCs no município, inclusive quanto à APA do VacacaíMirim.

Tal grupo está composto por representantes das seguintes entidades: Universidade Federal de Santa Maria (UFSM); Fundação MO’̃̃ Estudos e Pesquisas para a Proteção e o Desenvolvimento Ambiental; Secretaria Estadual do Meio Ambiente (SEMA) através do Departamento de Florestas e Áreas Protegidas (DEFAP); Instituto Brasileiro do Meio Ambiente e dos Recursos Naturais Renováveis (Ibama); Associação dos Professores Universitários de Santa Maria (APUSM).

A proposta de APA foi lançada inicialmente pelos representantes do Escritório Regional do Ibama de Santa Maria, em 2005. Nesta, propunha-se como área da UC a bacia hidrográfica do Rio Vacacaí-Mirim à montante da barragem do DNOS (Departamento Nacional de Obras de Saneamento), responsável por cerca de $40 \%$ da água que é tratada para o consumo de Santa Maria (RODRIGUES, 2006, p. 23).

Em 2009 ocorre a retomada das discussões referentes à efetiva criação desta UC, mais uma vez motivada pelo Ibama, sugerindo a ampliação de sua área levando em consideração a importância dos remanescentes florestais existentes na região. A partir de então começaram a ser realizadas reuniões no Escritório da Cidade da Prefeitura de Santa Maria, resultando na formação do citado Grupo de Trabalho, para dar continuidade às discussões.

O emergir das citadas propostas de UCs justifica-se principalmente pelas diferenciadas e belas paisagens que a área estudada proporciona, devido situar-se em uma faixa de transição geomorfológica.

O contato das rochas vulcânicas do Planalto com as rochas sedimentares, especialmente, as da bacia do Paraná, ocorre, de modo geral, através de um relevo escarpado. Essas características do relevo são propícias ao desenvolvimento de processos superficiais acelerados nos taludes naturais (erosões e movimentos de massa) e a preservação de uma vegetação do tipo florestal (ROBAINA; CRISTO; TRENTIN, 2011, p. 21). 
Este relevo escarpado é conhecido como Rebordo do Planalto Meridional, compondo a área de contato/transição entre as "terras altas" do Planalto gaúcho e as "terras baixas" da Depressão Central.

As características geomorfológicas e geológicas associadas ao clima condicionam a cobertura vegetal da área, com a presença predominante da Mata Atlântica. A decomposição de basaltos no Rebordo do Planalto forma solos ricos, que, acrescidos à umidade ocasionada por ventos de sul nas escarpas de front (voltadas ao sul), favorecem a existência da mata (AB'SÁBER, 2010).

(...) a forte taxa de umidade proveniente do avanço da massa de ar polar atlântica foi essencial para gerar oxissolos férteis e garantir um padrão de matas tropicais fora do espaço principal das matas atlânticas(AB'SÁBER, 2010, p.46).

O Domínio Tropical Atlântico estende-se latitudinalmente pelo litoral brasileiro e ainda interioriza-se, gerando diferenciados ecossistemas associados. No Rebordo do Planalto temos a Floresta Estacional Subtropical Decidual, que devido à variação térmica por um período do ano (baixas temperaturas), apresenta mais de 50\% de perda foliar do estrato superior da floresta, isto, devido a uma "seca fisiológica" (KILCA; LONGHI, 2011).

Devido à existência desta vegetação a área compõe a Reserva da Biosfera da Mata Atlântica no estado do Rio Grande do Sul, tombada pela UNESCO desde 1993 (CONSELHO NACIONAL DA RESERVA DA BIOSFERA DA MATA ATLÂNTICA, 2008). O território do município de Itaara é contemplado em sua totalidade pela Reserva da Biosfera, já o de Santa Maria possui sua porção norte inserida na mesma.O Plano Diretor de Santa Maria a promove como "Cidade Portal Sul da Reserva da Biosfera da Mata Atlântica” (SANTA MARIA, 2005).

$\mathrm{Na}$ área de estudo, além das Áreas de Preservação Permanente (APPs) de margens de cursos d'água, nascentes e declividades acentuadas, previstas pela legislação ambiental nos níveis federal e estadual, ainda existem as Áreas Especiais Naturais de Preservação Permanente, segundo a Lei de Uso e Ocupação do Solo de Santa Maria (LUOS), como: ado Morro Cechella, a do Morro do Monumento ao Ferroviário e a da Barragem do Vacacaí-Mirim. Todas estas incluem a área tombada como Reserva da Biosfera da Mata Atlântica, 
Nota-se que há uma sobreposição de áreas protegidas, confirmando a relevância dos atributos ambientais existentes. Mesmo a legislação estipulando normas para a proteção de tais áreas, até o momento todas as Áreas Especiais Naturais que foram instituídas legalmente não estão sendo submetidas a qualquer forma de manejo. Tomando Morsello (2008) como inspiração, aplica-se então o termo “Áreas Especiais Naturais de Papel" para os exemplos citados.

Com base na legislação ambiental que foi reportada e no reconhecimento das peculiaridades deste espaço, uma Unidade de Conservação da categoria Área de Proteção Ambiental comportaria as características das Áreas Especiais Naturais que a LUOS prevê, assim como seria uma alternativa adequada à realidade local quanto ao ordenamento territorial, à conservação dos recursos hídricos e dos remanescentes de Mata Atlântica existentes.

\section{METODOLOGIA}

O método dedutivo de pesquisa científica norteia esse trabalho. Alves (1981, p. 116-7) afirma que na dedução adota-se um conhecimento geral, uma afirmação válida que pode ser demonstrada ao examinarmos o objeto de estudo a partir de determinada lei geral.

E o conhecimento adotado aqui provém do conceito de paisagem, a partir da abordagem sistêmica, proporcionando uma visão holística e auxiliando na análise do espaço estudado.

Entre os procedimentos metodológicos, menciona-se o acompanhamento de reuniões junto a grupos de pesquisa, organizações ambientalistas e órgãos públicos gestores do meio ambiente, já que esta pesquisa surgiu com embasamento nas discussões locais sobre áreas protegidas, que tem ocorrido desde 2009.

Desta forma, o método e a abordagem utilizados são complementados pelo contexto político local quanto às áreas protegidas, acreditando que ao considerar tal aspecto os resultados possam ser mais coerentes e com uma aplicação viável frente aos entraves que existem na efetivação e na gestão de uma UC.

Bensusan (2006) comenta sobre a angustiante missão que é a escolha do desenho de uma área protegida. Para fins de delimitação da APA utiliza-se como referência os 
procedimentos sugeridos por Cabral e Souza (2005) e os escritos de Romero e Jimenez (2002) sobre o modelo de Bertrand. Então, para Cabral e Souza (2005) a delimitação de uma APA deve observar:

1. O recorte amplo da área, considerando os atributos ambientais que motivaram a criação da APA para, a partir disso, realizar os ajustes necessários no sistema em estudo.

2. A identificação da ocorrência de atributos ambientais que se deseja proteger em áreas onde é permitido e desejável o desenvolvimento econômico de atividades dentro dos limites de capacidade de suporte dos ecossistemas naturais.

3. A ponderação dos atributos ambientais que motivam a criação da unidade de conservação, no sentido de hierarquizar prioridades para preservação. Essa etapa, por ser subjetiva, deve ser motivada com a participação da sociedade e acompanhada por profissionais de diversos ramos do conhecimento.

4. A localização espacial desses atributos ambientais dentro do sistema em estudo, separando-os em mapas temáticos.

5. O cruzamento de informações espacializadas, por meio de análise integrada dos recursos ambientais.

6. A identificação das áreas de ocorrência de interseção dos atributos ambientais que motivam a criação da unidade de conservação.

7. A priorização de divisores de bacias hidrográficas como delimitadores da unidade de conservação, garantindo que em seu interior seja contemplado o maior número possível das áreas anteriormente mencionadas.

8. A identificação de elementos físicos, por exemplo, vertentes como divisas da unidade de conservação, incluindo em seu perímetro, por meio da legislação que a criou ou regulamentou, as Áreas de Preservação Permanente instituídas pelo Código Florestal.

Complementando o que foi ressaltado por Cabral e Souza, a determinação do limite da APA do Vacacaí-Mirim ainda terá como suporte a definição de unidades da paisagem a partir da aplicação do modelo desenvolvido por Bertrand na década de 1960 e aplicado eficazmente por García-Romero no México. O modelo “Análisis Integrado de Paisages" é composto por quatro etapas (ROMERO; JIMÉNEZ, 2002): 
a) Inventário geoecológico: reconhecimento dos componentes do território, como relevo, vegetação e uso do solo, assim como geração de mapas temáticos.

b) Estabelecimento da estrutura taxonômica-corológica: diferenciação hierarquizada de unidades da paisagem, segundo o nível que ocupam - zona, domínio, região natural, geossistema, geofácie e geotopo.

c) Análise das paisagens elementares: estudo dos geossistemas do território a partir do reconhecimento das unidades inferiores (geofácies).

d) Síntese estrutural e dinâmica: apresentam-se os resultados finais a respeito do estado atual dos recursos, do grau de ocupação humana e dos processos associados a esta.

Diga-se que a discriminação de unidades da paisagem deu-se na ampla área de estudo, abrangendo áreas externas à atual delimitação do território da UC proposta por NASCIMENTO (2010), assim, auxiliando na redefinição perimétrica da mesma. Também, que neste artigo o objetivo foi cumprido aplicando somente as três primeiras etapas do modelo “Análisis Integrado de Paisages".

Os mapeamentos necessários à pesquisa foram realizados a partir do emprego da versão 4.3.3 do software livre SPRING - Sistema de Processamento de Informações Georreferenciadas, criado em 1991 pelo Instituto Nacional de Pesquisas Espaciais (INPE). Neste, utilizou-se imagem de satélite disponível no Google Earth, também um software livre, que data da primavera de 2011.

No SPRING foi realizada a digitalização das cartas topográficas Santa Maria NE, SE, SO e Camobi SO, elaboradas pela Diretoria do Serviço Geográfico do Exército Brasileiro em 1980, em escala 1:25000. Esta escala é adequada a planejamentos ligados à avaliação das potencialidades de uso e proposição de zoneamento (SANTOS, 2004).

A delimitação da APA resultou da sobreposição de informações de mapas temáticos que foram gerados: unidades da paisagem, bacias hidrográficas, estradas e uso e ocupação da terra.

Os procedimentos metodológicos ainda contaram com trabalhos de campo, buscando aumentar o conhecimento sobre a área. Nestes, além dos registros fotográficos indispensáveis a apresentação de características da APA, foram verificadas algumas 
informações in loco, que não foram alcançadas através do geoprocessamento, auxiliando na descrição e no entendimento deste espaço geográfico.

\section{RESULTADOS}

\section{As unidades da paisagem}

A hierarquia das unidades da paisagem considerada no mapeamento realizado na grande área de estudo partiu do reconhecimento de quais seriam os domínios e da reflexão sobre possíveis geofácies e geotopos. Portanto, mapearam-se os níveis região e geossistema, utilizando-se critérios geomorfológicos, já que uma característica importante do objeto de estudo é a existência de uma transição geomorfológica.

O levantamento sobre as unidades geomorfológicas está assentado nos estudos de Pereira et al. (1989), que utilizam-se dos conhecimentos de Ab' Saber sobre os Domínios Morfoclimáticos. Quanto a tais domínios têm-se na grande área o Domínio Morfoclimático das Araucárias e o Domínio Morfoclimático das Pradarias. No primeiro inserem-se as unidades de relevo do Planalto, no segundo, a Depressão Periférica.

Primeiramente buscou-se delimitar as regiões do Planalto e da Depressão. Considerou-se como Planalto a área situada a partir da cota altimétrica de $150 \mathrm{~m}$, onde iniciam-se acentuadas declividades até alcançar as maiores altitudes da área (em torno de 470 m). Já a Depressão foi determinada como a área com altitudes abaixo dos $150 \mathrm{~m}$ chegando a menos de $80 \mathrm{~m}$, com relevo mais suave. Na figura 2 visualizam-se as unidades da paisagem mapeadas no objeto de estudo.

Ainda distinguiram-se quatro geossistemas: Geossistema do Topo do Planalto e Geossistema do Rebordo do Planalto pertencentes à Região do Planalto, e, Geossistema das Coxilhas e Geossistema das Planícies situados na Região da Depressão (ver figura 2). 


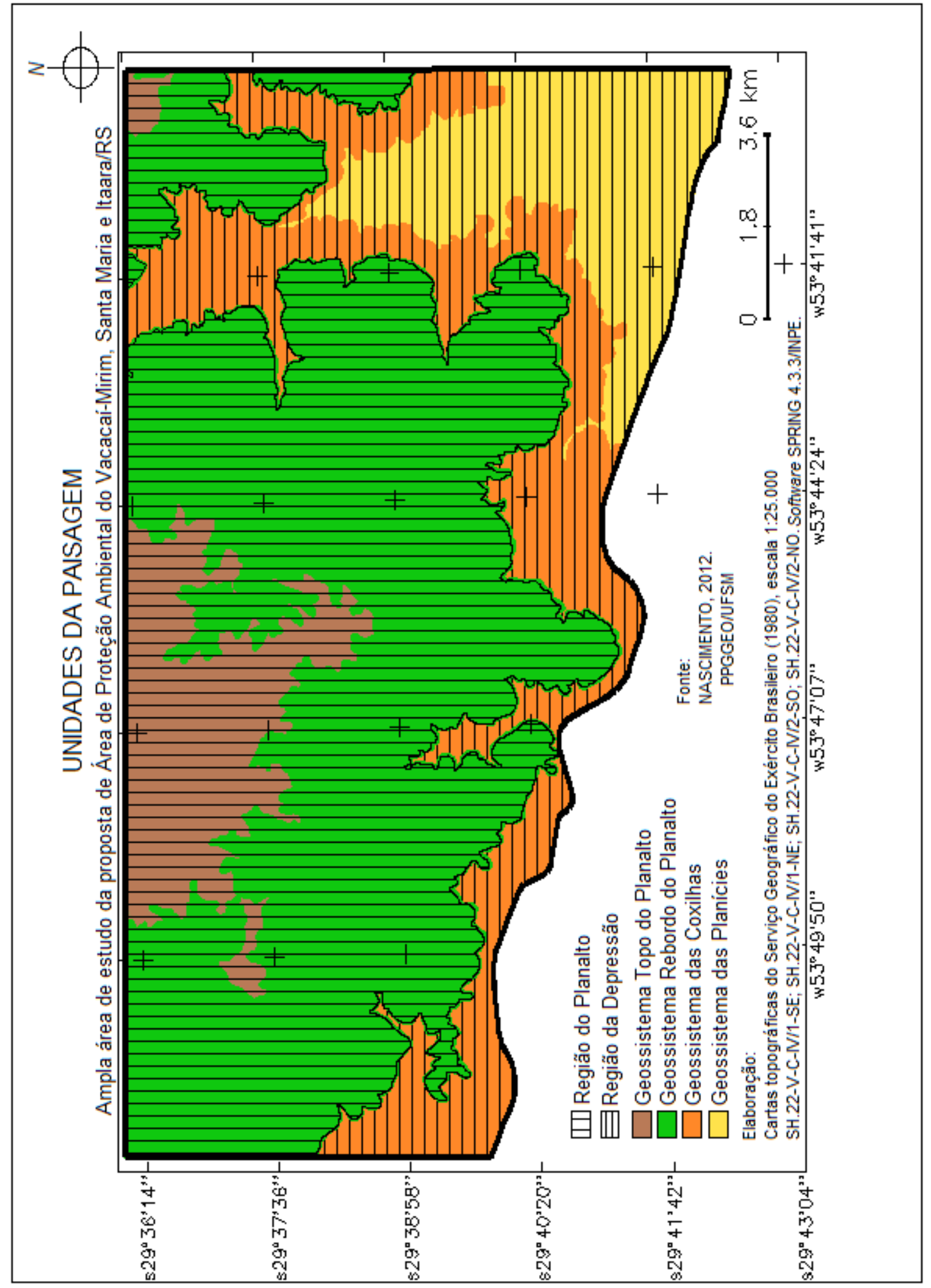

Figura 2- Unidades da paisagem na ampla área de estudo.

Fonte: Mapeamento realizado na pesquisa. 
Para demarcar o Geossistema Topo do Planalto procurou-se identificar o que a caracteriza. Segundo Pereira et al. (1989) sua topografia é fracamente ondulada, com coxilhas esculpidas em rochas vulcânicas resistentes, possuindo declividades predominantes de $8 \%$ e ainda menores, e, altitudes entre 340 e $520 \mathrm{~m}$.

Através da interpretação dos mapas hipsométrico e clinográfico gerados na pesquisa, determinou-se que a partir da cota de $400 \mathrm{~m}$ a área seria considerada Topo do Planalto. Verificou-se que o uso e ocupação da terra em tal unidade é predominantemente antrópico, com núcleos urbanos, lagos artificiais e silvicultura.

A unidade da paisagem Rebordo do Planalto, após delimitada, confirmou a hipótese inicial do trabalho, apresentando a maior porção de remanescentes de Mata Atlântica, apesar de existirem usos e ocupações antrópicas, principalmente nos vales dos rios Manoel Alves (agropecuária predominante) e Vacacaí-Mirim à montante de sua barragem (urbanização). A faixa entre 150 e 400 m de altitude demarcou esta unidade, caracterizada por acentuadas declividades, em média 45,5\%.

O Geossistema das Coxilhas é de fácil demarcação perante o Rebordo do Planalto, apresentando colinas côncavo-convexas, colinas tabuliformes e planícies aluviais (PEREIRA et al., 1989), portanto, suas maiores altitudes estão representadas pela cota de $150 \mathrm{~m}$, que delimita a própria unidade do Rebordo do Planalto. A menor cota é $90 \mathrm{~m}$, onde a declividade começa a suavizar consideravelmente.

No Geossistema das Coxilhas afloram lençóis de água e formam-se banhados, que são bem-vindos no quadrante leste da área de estudo, que possui predominância de atividade agrícola. Já na porção sul/sudoeste há intensa ocupação urbana. Percebe-se que em ambas as áreas ocorre a supressão da vegetação original devido à expansão das atividades humanas.

A unidade Geossistema das Planícies abrange altitudes de $90 \mathrm{~m}$ chegando até pouco mais de $70 \mathrm{~m}$ (na área de estudo) e a declividade é suave, de $2 \%$ e até menos que isto. O uso da terra é intensamente agrícola, com muitas lavouras de arroz nas proximidades dos rios Vacacaí-Mirim (à jusante da barragem), Arroio Grande, Arroio do Meio e Arroio do Veado.

Após a exposição dos critérios definidores e das características de cada unidade da paisagem mapeada, justifica-se o porquê da definição do Topo do Planalto, Rebordo do Planalto, Coxilhas e Planícies como sendo do nível hierárquico do geossistema. 
Apesar de cotas altimétricas demarcarem suas abrangências, não somente isto foi considerado, já que o geossistema é composto por elementos bióticos e abióticos.

As paisagens que dão ao objeto de estudo o potencial para ser uma Unidade de Conservação devem-se justamente à morfologia da região, que condiciona juntamente com o clima a existência da vegetação de Mata Atlântica e formações vegetais complexas devido à zona de transição para o bioma Pampa. Aliás, o próprio relevo tem servido como certo bloqueio a uma maior expansão urbana ou rural.

Enfim, não somente as atividades humanas integram os fatores bióticos do geossistema, mas a própria vegetação e seus ecossistemas associados. Também, comprova-se pelos mapeamentos desta pesquisa que o fator abiótico relevo é um condicionante fundamental na formação destas diferenciadas paisagens. Sobre a temática:

\footnotetext{
La vegetación es el elemento más característico del paisaje, aquel al que se le reconoce el carácter de integrador del resto de factores que intervienen en el medio natural. La vegetación es (...) el fiel reflejo de las complejas relaciones que se establecen entre el pueblo, el clima, el substrato rocoso, los factores topográficos y ella misma, al mismo tiempo que sirve de hábitat para la mayor parte de especies animales y desempeña a menudo un papel de reveladora muestra del grado de intervención humana (INSA, 1992, p. 235).
}

Ainda, para considerar as unidades citadas como geossistemas necessitou-se de uma reflexão sobre os níveis inferiores a ele, ou seja, houve a reflexão sobre geofácies e geotopos, mesmo que não tenham sido mapeados.

Para demonstrar o raciocínio alguns exemplos: uma geofácie do Geossistema das Planícies poderia ser a "Geofácie das Residências" com o "Geotopo dos Jardins"; quanto ao Geossistema do Rebordo do Planalto uma geofácie poderia ser a "Geofácie da Exploração de Basalto" que possui o "Geotopo da Face Noroeste da Superfície de Exploração", ou, "Geofácie Urbana" com um “Geotopo do Posto de Combustível”.

Salienta-se que não ocorreu a preocupação com o refinamento da delimitação das unidades da paisagem, por isto não foram demonstradas faixas de transição entre elas, com a finalidade de explicitar que ocorrem diferentes estruturas e fluxos no espaço até que passe a ser considerada uma unidade distinta. Porém, para a intenção deste trabalho, que é obter mais um argumento para auxiliar na definição do perímetro de uma 
UC, tal mapeamento é satisfatório, até porque os limites estabelecidos não demonstram transições abruptas.

\section{Estabelecendo os limites espaciais, mas ampliando o alcance da proteção ambiental}

Para estabelecer um perímetro para a APA do Vacacaí-Mirim foram utilizados temas que contemplam elementos bióticos e abióticos da ampla área de estudo, são eles: unidades da paisagem, bacias hidrográficas, estradas e uso e ocupação da terra. A figura 3 demonstra os mesmos e exemplifica uma sobreposição de temas para a finalidade de demarcação da APA.

$\mathrm{Na}$ primeira interpretação dos temas sobrepostos priorizou-se que alguns elementos deveriam compor a UC, como: a área de captação da bacia hidrográfica do Rio Vacacaí-Mirim à montante de sua barragem, que foi o foco das discussões iniciais sobre tal área protegida, dando nome à proposta de UC, e, a predominância da unidade da paisagem Geossistema Rebordo do Planalto, que possui a maior parte dos remanescentes de Mata Atlântica.

É sabido que a intensa presença de estradas em uma UC pode trazer malefícios à mesma, como o efeito degradante em suas bordas, porém, nesta delimitação buscou-se utilizá-las como facilitadoras na determinação dos limites. Por serem facilmente identificadas no terreno, podem colaborar no planejamento político e administrativo da APA.

Já o mapa de uso e ocupação da terra propicia a observação da cobertura vegetal (predominante na área) e das interferências antrópicas no espaço, permitindo a identificação de paisagens já fortemente modificadas, que ficaram em sua maioria externas à APA, mesmo que tal UC permita uso urbano e/ou rural em seu território. 
Temas considerados na delimitação da APA
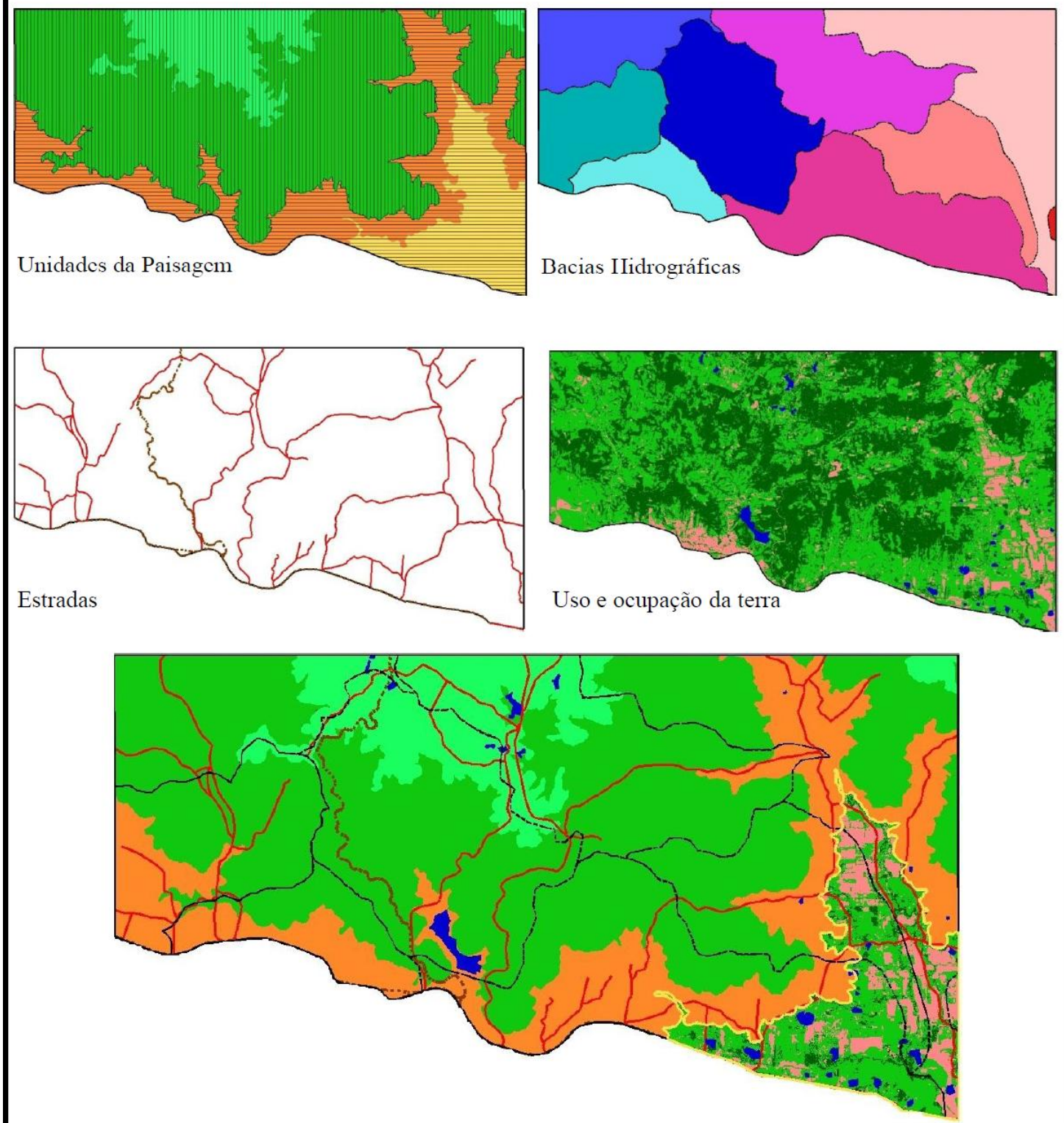

Exemplo de sobreposição de temas

Figura 3- Temas utilizados na delimitação da APA.

Fonte: Mapeamentos realizados na pesquisa.

Cabe então fazer um memorial descritivo da delimitação (acompanhe as figuras 3 e 4), com início a partir do quadrante norte do objeto de estudo. Como ponto inicial parte-se do encontro da rodovia BR 158 com a Estrada do Perau em frente à SOCEPE (Sociedade Concórdia de Caça e Pesca), a partir de então se segue em sentido antihorário por uma estrada municipal de Itaara que leva a Vila Etelvina e perpassa ostrilhos 
da ferrovia. Adiante no sentido sudoeste segue-se a caminho rural até o encontro com a estrada que liga Santa Maria ao município de São Martinho da Serra, seguindo ao sul até deparar-se com a cota altimétrica de $150 \mathrm{~m}$.

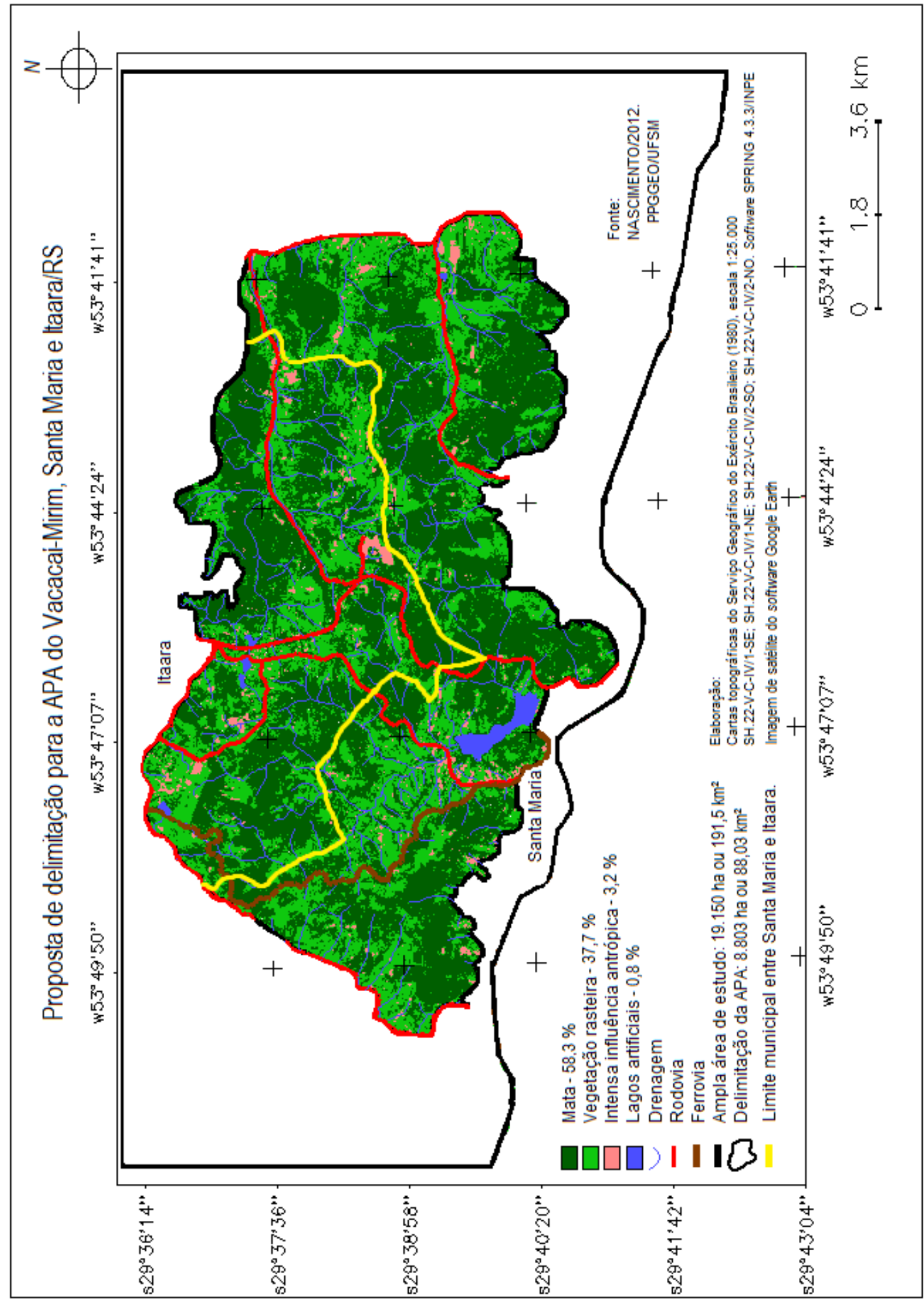

Figura 4- Delimitação da APA do Vacacaí-Mirim. 
Fonte: Mapeamento realizado na pesquisa.

Percebe-se na descrição a prevalência de estradas como limite, crê-se que além de facilitar a visualização do que seria o espaço da APA, ainda incorpora satisfatoriamente a bacia hidrográfica de captação da barragem do Rio Vacacaí-Mirim, como significativa área de Rebordo do Planalto.

A cota de 150 m estende-se nos sentidos leste e sudeste ao encontro da Rua República do Líbano em sua junção com a Rua Doutor Antônio Victor Menna Barreto. Deste ponto projeta-se uma linha reta na direção nordeste até a intersecção da Rua Euclides da Cunha com a ferrovia, sendo a última o limite que contorna o quadrante sul do Morro Cechella de encontro ao divisor de águas das bacias do Rio Vacacaí-Mirim à montante e à jusante da barragem. A partir de então se considera o divisor de águas até encontrar a rodovia, sendo esta o delimitador (orientação sul) que topa com a cota de $150 \mathrm{~m}$.

O último parágrafo remete-se a cotas altimétricas, ruas, ferrovia e divisor de águas. Esta diversidade deve-se ao fato de ser a área com maior urbanização presente nesta proposta de APA. Elementos importantes como o Morro das Antenas, Morro Link, Monumento ao Ferroviário e Morro Cechella foram contemplados para compor o interior da APA.

É mantida como limite a curva de nível correspondente aos $150 \mathrm{~m}$ até que a mesma depare-se com o divisor de águas das bacias do Arroio do Meio e do Rio Vacacaí-Mirim à jusante de seu barramento, que é mantido até encontrar a leste a estrada Norberto José Kipper. Este traçado demarca uma das mais belas paisagens que pode avistar-se a partir da zona leste da cidade de Santa Maria (próximo à Universidade Federal), englobando escarpas do Rebordo do Planalto ainda com bastante cobertura de mata, como o Morro do Elefante.

Da estrada Norberto José Kipper projeta-se para norte uma estrada rural que delimita a APA até encontrar-se com o divisor de águas dos Arroios Manoel Alves e Arroio Grande. Este divisor (orientações oeste e noroeste) é o limite que segue de encontro à cota de $400 \mathrm{~m}$, sendo esta seguida até chegar à rodovia, e, na direção sul encontrar o ponto inicial desta descrição, o encontro da rodovia BR $158 \mathrm{com}$ a Estrada do Perau em frente à SOCEPE. 
A última descrição abarca os vales dos rios Arroio do Meio e Arroio Manoel Alves, que possuem vastas áreas do Geossistema Rebordo do Planalto ainda conservadas. É no vale do Manoel Alves que se encontra uma RPPN (Reserva Particular do Patrimônio Natural) em fase de instituição, a RPPN MO’Ã.

Admite-se que onde a delimitação seguiu cotas altimétricas o delineado da proposta de UC ficou com uma não tão fácil assimilação. Porém, foram incorporadas áreas relevantes em se tratando dos remanescentes de Mata Atlântica.

Ainda, a redefinição perimétrica da proposta de APA proporcionou um "desenho" mais apropriado para fins de conservação do que o proposto por NASCIMENTO em 2010, como se observa na ilustração que segue.

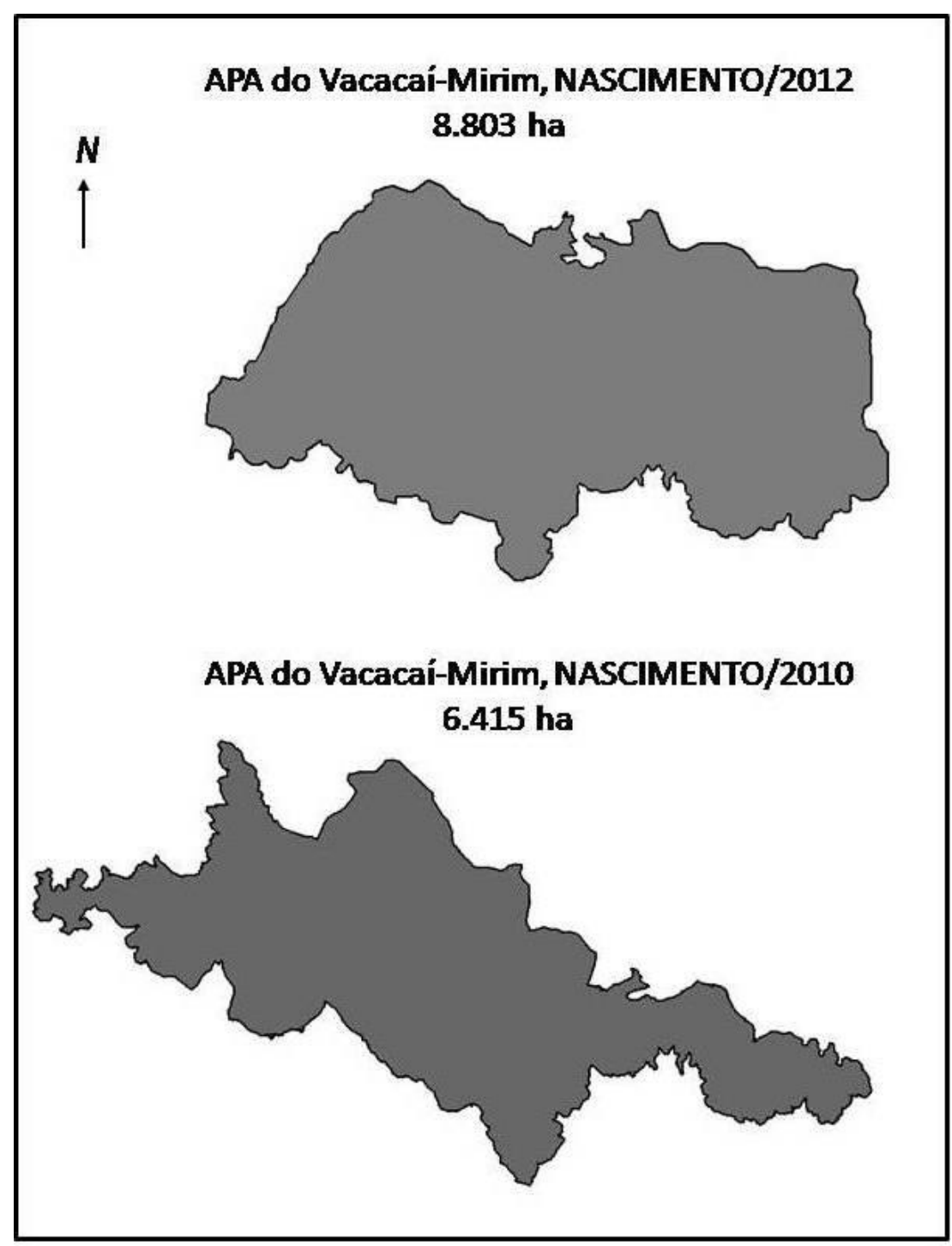


Figura 5- Comparação entre as duas propostas de território para a APA do VacacaíMirim.

Fonte: NASCIMENTO, 2010; mapeamentos da presente pesquisa.

Nota-se que a proposta de 2012 apresenta uma superfície maior, como um formato mais arredondado se comparado a de 2010, mais alongada e estreita. Os fatores forma mais arredondada e maior quantidade de hectares são importantes, já que para a conservação maiores áreas são melhores que áreas menores (INSA, 1992), como, formatos mais circulares diminuem a degradação do ambiente em relação ao efeito de borda sobre a vegetação (METZGER, 2006).

Finalizando, a proposta totalizou uma área de $88 \mathrm{~km}^{2}$, sendo que $59 \%$ desta está situada no território municipal de Santa Maria e 41\% no município de Itaara (quadrante norte da APA).

\section{CONSIDERAÇÕES FINAIS}

A nova delimitação dada à APA do Vacacaí-Mirimampliou sua abrangência em relação às outras propostas existentes, predominando nesta a unidade da paisagem Rebordo do Planalto. Também, o formato gerado é mais adequado à conservação, principalmente se comparado a proposição de NASCIMENTO em 2010.

Além de proteger as belas paisagens que satisfazem os olhos de quem as miram, se adequadamente manejada, a APA proporcionaria a regeneração vegetal de algumas áreas desmatadas, como o restabelecimento da fauna e qualificaria a produção de água, tão importante na bacia hidrográfica que dá nome a esta UC.

Depois de instituída a APA do Vacacaí-Mirim poderá compor a Zona Núcleo da Reserva da Biosfera da Mata Atlântica, quando da atualização de seu tombamento, já que entre os critérios de composição de tal zona estão os territórios de UCs. Este fato deve configurar-se como um estímulo aos municípios de Santa Maria e Itaara, apesar do desafio que possa parecer criar esta UC conjuntamente.

\section{REFERÊNCIAS}

AB'SÁBER, A. N. Os domínios de natureza no Brasil: potencialidades paisagísticas. 6. Ed. São Paulo: Ateliê Editorial, 2010. 
ALVES, R. Filosofia da Ciência: introdução ao jogo e suas regras. São Paulo: Editora Brasiliense, 1981. 210 p.

BENSUSAN, N. Conservação da biodiversidade em áreas protegidas. Rio de Janeiro: Editora FGV, 2006. 176 p.

BRASIL. Constituição da República Federativa da Brasil de 1988. Diário Oficial [da] Presidência da República, Casa Civil, Brasília, DF, 5 out. 1988. Disponível em: $<$ http://www.planalto.gov.br/ccivil_03/constituicao/constitui\%C3\%A7ao.htm> Acesso em: 25 jun. 2009.

. Lei n. 9.985, de 18 de julho de 2000. Regulamenta o art. $225, \S 1^{\circ}$, incisos I, II, III e VII da Constituição Federal, institui o Sistema Nacional de Unidades de Conservação da Natureza e dá outras providências. Diário Oficial [da] Presidência da República: Casa Civil, Brasília, DF, 18 jul. 2000. Disponível em: <http://www.planalto.gov.br/ccivil_03/leis/19985.htm>. Acesso em: 05 ag. 2009.

. Decreto n. 4.297, de 10 de julho de 2002 a. Regulamenta o art. 9ํㅜ, inciso II, da Lei n⿳0 6.938, de 31 de agosto de 1981, estabelecendo critérios para o Zoneamento Ecológico-Econômico do Brasil - ZEE, e dá outras providências. Diário Oficial [da] Presidência da República: Casa Civil, Brasília, DF, 10 jul. 2002. Disponível em: <http://www.planalto.gov.br/ccivil/decreto/2002/D4297.htm>. Acesso em: 17 jan. 2011.

Decreto n. 4.340, de 22 de agosto de 2002 b.Regulamenta artigos da Lei $\mathrm{n}^{\mathrm{o}}$ 9.985, de 18 de julho de 2000, que dispõe sobre o Sistema Nacional de Unidades de Conservação da Natureza - SNUC, e dá outras providências.Diário Oficial [da] Presidência da República: Casa Civil, Brasília, DF, 22 ag. 2002. Disponível em: <http://www.planalto.gov.br/ccivil_03/decreto/2002/d4340.htm>. Acesso em: 17 jan. 2011.

CABRAL, N. R. A. J.; SOUZA, M. P. de. Área de Proteção Ambiental: planejamento e gestão de paisagens protegidas. São Carlos: RiMa, 2005. 158 p.

CONSELHO NACIONAL RESERVA DA BIOSFERA DA MATA ATLÂNTICA. Reserva da Biosfera da Mata Atlântica Fase VI/2008: revisão e atualização dos limites e zoneamento da Reserva da Biosfera da Mata Atlântica em base cartográfica digitalizada. São Paulo: Conselho Nacional da Reserva da Biosfera da Mata Atlântica, 2008. 127 p. Disponível em: <http://www.rbma.org.br/rbma/rbma fase_vi.asp > Acesso em: 06 jun. 2010.

FIRKOWSKI, C. APA: fatos, desejos sonhados e propagandice. Natureza \& Conservação, Curitiba,v. 5, n. 1, abril, p. 8-14, 2007. Disponível em: $<$ http://www.fundacaogrupoboticario.org.br/PT-BR/Paginas/quemsomos/default.aspx\#> Acesso em: 14 jul. 2010.

INSA, J. S. Los espacios naturales. In.: BOLÓS, M. de. (Org.). Manual de ciencia del paisaje:teoria, métodos y aplicaciones. Barcelona, 1992. p. 233-248. 
KILCA, R. V.; LONGHI, S. J. Composição florística e a estrutura das florestas secundárias no rebordo do Planalto Meridional. In.: SCHUMACHER, M. V. et al (Org.). A floresta estacional subtropical: caracterização e ecologia no rebordo do planalto meridional. Santa Maria, 2011. p. 53-83.

METZGER, J. P. Como lidar com as regras pouco óbvias para conservação da biodiversidade em paisagensfragmentadas.Natureza \& Conservação, Curitiba, v.4, n. 2, out., p. 11-23, 2006. Disponível em: <http://www.fundacaogrupoboticario.org.br/PTBR/Paginas/quem-somos/default.aspx\#> Acesso em: 14 jul. 2010.

MORSELLO, C. Áreas protegidas públicas e privadas: seleção e manejo. 2. ed. São Paulo: Annablume, 2008. 344 p.

NASCIMENTO, D. B. do. Proposta de Unidade de Conservação: Área de Proteção Ambiental (APA) do Vacacaí-Mirim/RS. 2010. 53 f. Trabalho de Graduação (Licenciatura em Geografia) - Departamento de Geociências, Universidade Federal de Santa Maria, Santa Maria, 2010.

NASCIMENTO, D. B. do. Área de Proteção Ambiental do Vacacaí-Mirim/RS: uma proposta para sua delimitação espacial. 91 f. Dissertação de Mestrado (Geografia) Departamento de Geociências, Universidade Federal de Santa Maria, Santa Maria, 2012.

PÁDUA, M. T. J. Do Sistema Nacional de Unidades de Conservação. In.: MEDEIROS; ARAÚJO (Org.). Dez anos do Sistema Nacional de Unidade de Conservação da Natureza: lições do passado, realizações presentes e perspectivas para o futuro. Brasília: MMA, 2011. p. 21-36.

PEREIRA, P. R. B.; NETTO, L. da R. G.; BORIN, C. J. A.; SARTORI, M. da G. B. Contribuição à Geografia Física do município de Santa Maria: unidades de paisagem. GeografiaEnsino \& Pesquisa, Santa Maria, v. 3, dez., p.37-68, 1989.

ROBAINA, L. E. de S.; CRISTO, S. S. V. de; TRENTIN, R. Considerações geológicas e geomorfológicas sobre o rebordo do Planalto Meridional no Rio Grande do Sul. In.: SCHUMACHER, M. V. et al (Org.). A floresta estacional subtropical: caracterização e ecologia no rebordo do planalto meridional. Santa Maria, 2011. p. 21-31.

RODRIGUES, B. R. C. Levantamento de Uso e Conflitos da Terra da Área de Captação da Barragem do DNOS na Área de Proteção Ambiental (APA) no Rio Vacacaí-Mirim/RS. 101 f. Monografia (Especialização em Geografia) - Universidade Federal de Santa Maria, Santa Maria, 2006.

ROMERO, A. G.; JIMÉNEZ, J. M. El Paisage en el Ámbito de la Geografía.Cidade do México: UNAM, 2002. 
SANTA MARIA. Lei complementar municipal n. 034 de 29 de dezembro de 2005.Dispõe sobre a Política de Desenvolvimento Urbano e sobre o Plano Diretor de Desenvolvimento Urbano Ambiental do Município de Santa Maria. Prefeitura Municipal de Santa Maria, Santa Maria, RS, 29 dez. 2005. Disponível $\mathrm{em}:<$ http://www.santamaria.rs.gov.br/_secretarias/pdf/ArqSec44.pdf $>$ Acesso em: 25 jun. 2009.

.Lei complementar municipal n. 033 de 29 de dezembro de 2005. Institui a Lei de Uso e Ocupação do Solo, Parcelamento, Perímetro Urbano e Sistema Viário do Município de Santa Maria. Prefeitura Municipal de Santa Maria, Santa Maria, RS, 29 dez. 2005. Disponível em:

<http://www.santamaria.rs.gov.br/_secretarias/pdf/ArqSec33.pdf > Acesso em: 20 abr. 2009.

.Lei complementar municipal n. 072 de 4 de novembro de 2009. Institui a Lei de Uso e Ocupação do Solo, Parcelamento, Perímetro Urbano e Sistema Viário do Município de Santa Maria.Prefeitura Municipal de Santa Maria, Santa Maria, RS, 4 nov. 2009. Disponível em:

$<$ http://www.santamaria.rs.gov.br/docs/secretarias/ArqSec159.pdf $>$ Acesso em: 27 mar. 2010.

.Lei municipal n. 5285 de 15 de janeiro de 2010. Dispõe sobre a criação das Reservas Particulares do Patrimônio Natural - RPPNs - no Município de Santa Maria e dá outras providências. Prefeitura Municipal de Santa Maria, Santa Maria, RS, 15 jan. 2010. Disponível em: <http://www.camarasm.rs.gov.br/2010/?conteudo=busca_legislacao\&busca=busca> Acesso em: 18 abr. 2011.

SANTOS, R. F. dos. Planejamento ambiental: teoria e prática. São Paulo: Oficina de Textos, 2004. 184 p.

VIANA, M. B.; GANEM, R. S. APAs federais no Brasil. Brasília, DF: Câmara dos Deputados, 2005.49 p. Disponível em: <http://www2.camara.gov.br/documentos-epesquisa/publicacoes/estnottec/tema14> Acesso em: 13 mar. 2011.

Artigo recebido para publicação em dez/13.

Artigo aceito para publicação em março/14. 